\title{
Large trees are keystone structures in urban parks
}

\author{
Karen Stagoll ${ }^{1}$, David B. Lindenmayer ${ }^{1}$, Emma Knight $^{2}$, Joern Fischer ${ }^{1,3}$, \& Adrian D. Manning ${ }^{1}$ \\ ${ }^{1}$ The Fenner School of Environment and Society, The Australian National University, Canberra, ACT 0200, Australia \\ ${ }^{2}$ Centre for Mathematics and its Applications, The Australian National University, Canberra, ACT 0200, Australia \\ ${ }^{3}$ Department of Sustainability Sciences, Leuphana University Lueneburg, 21335 Lueneburg, Germany
}

\section{Keywords}

Birds; city parks; science-based management; scattered trees; southeastern Australia; tree preservation; urban biodiversity; urban conservation policy; urban ecology; urban forest.

\section{Correspondence}

Karen Stagoll, The Fenner School of

Environment and Society, Building 48, Linnaeus

Way, The Australian National University,

Canberra, ACT, 0200, Australia.

Tel: +61 (0)2 6125 1494; Fax: +61 (0)2 6125

0757. E-mail: karen.stagoll@anu.edu.au

\section{Received}

11 September 2011

Accepted

12 December 2011

Editor

Wayne Linklater

doi: 10.1111/j.1755-263X.2011.00216.x

\begin{abstract}
Large trees are considered keystone structures in agricultural and forestry production landscapes, but research demonstrating this in urban landscapes is urgently needed. If large trees are keystone structures in urban parks, it is imperative that this is recognized in policy to ensure their ongoing existence. We studied the role of large native trees for birds in urban parks in Canberra, Australia. We found that (1) large trees had a consistent, strong, and positive relationship with five measures of bird diversity, and (2) as trees became larger in size, their positive effect on bird diversity increased. Large urban trees are therefore keystone structures that provide crucial habitat resources for wildlife. Hence, it is vital that they are managed appropriately. With evidencebased tree preservation policies that recognize biodiversity values, and proactive planning for future large trees, the protection and perpetuation of these important keystone structures can be achieved.
\end{abstract}

\section{Introduction}

The worldwide decline of mature trees has recently become a topic of conservation concern (Manning et al. 2006; Vesk \& Mac Nally 2006; Gibbons et al. 2008; deMars et al. 2010; Fischer et al. 2010a; Rolo \& Moreno 2011). Their loss will have negative consequences for biodiversity and associated ecosystem services (Fischer et al. 2009, 2010a, and references therein).

Large trees are considered keystone structures because they provide "resources, shelter, or 'goods and services' crucial for other species" (Tews et al. 2004, p. 86; also see Manning et al. 2006; Fischer et al. 2010a). They provide critical habitat for a range of taxa, including bats (e.g., Lumsden \& Bennett 2005; Fischer et al. 2010a, b), ground-dwelling, and arboreal mammals (e.g., Gibbons \& Lindenmayer 2002; Mazurek \& Zielinski 2004; Lindenmayer et al. 2011), birds (e.g., Poulson 2002; Loyn
\& Kennedy 2009; deMars et al. 2010; Seymour \& Dean 2010; Stagoll et al. 2010), and invertebrates (e.g., Sirami et al. 2008; Carpaneto et al. 2010). Large trees are important for the production of coarse woody debris (Killey et al. 2010) and provide a distinct microclimate, with increased soil nutrients, plant species richness and structural complexity (Manning et al. 2006). Furthermore, large trees fulfill a range of landscape-scale ecological functions, including increasing habitat connectivity, which may facilitate species' range expansions and thus capacity to adapt to climate change (Manning et al. 2009). In addition to these biological functions, large trees are also important socially, culturally, and aesthetically (Jim 2004, 2005).

Research on the value of large trees has primarily been undertaken in forestry production areas (e.g., Lindenmayer \& Franklin 1997; Mazurek \& Zielinski 2004; Gibbons et al. 2010; Lindenmayer et al. 2011) and, more 
recently, agricultural landscapes (e.g., Gibbons \& Boak 2002; Sirami et al. 2008; deMars et al. 2010; Seymour $\delta$ Dean 2010). From this research, it can be predicted that large trees should also play an important function in urban landscapes. However, most previous work has focused on their role in atmospheric pollution and carbon dioxide reduction, energy reduction, stormwater runoff mitigation, and provision of aesthetic (e.g., personal wellbeing, recreation, and property value) benefits (Jim 2004; Millward \& Sabir 2011, and references therein). In comparison, the decline of large urban trees and their value to biodiversity has received much less attention (but see Jim 2005; Grigg et al. 2009). Recent work, however, in Italy (Carpaneto et al. 2010), Mexico (Ortega-Alvarez \& MacGregor-Fors 2010), and Australia (Harper et al. 2005) suggests that large trees provide important habitat structures for a variety of urban wildlife. However, the protection and perpetuation of large trees in urban areas sometimes conflicts with other urban policies, such as public safety measures (e.g., Carpaneto et al. 2010) and sustainable growth strategies that increase residential density (Pauleit et al. 2005). Therefore, more research demonstrating the crucial value of large trees in urban areas is urgently needed.

We present a case study on the value of large trees in urban parks for birds. We asked: (1) do large trees have a consistent, positive, and strong effect on bird diversity? We investigated five measures of bird diversity directly relevant to the keystone role of large trees: (i) bird species richness, and (ii) abundance, as an indication of the availability and quality of habitat resources for birds; (iii) incidence of breeding, as an indication of the fitness (reproduction and survival) of individual species; (iv) woodland-dependent species richness; and (v) community structure, as an indication of how large trees can alter species assemblages. In addition, we asked: (2) how large do trees need to be to have an effect on bird diversity? We expected that as the minimum trunk diameter threshold for "large" trees increases, the strength of the effect of these trees on the various measures of bird diversity also would increase.

\section{Methods \\ Study area}

We conducted our study in Canberra, Australian Capital Territory (ACT), in southeastern Australia. Canberra is approximately $800 \mathrm{~km}^{2}$, and has a population of 362,000 people. Population density is approximately 452 people per $\mathrm{km}^{2}$ (ABS 2010). The city is known as the "Bush Capital" and there is substantial urban tree cover across public and private land. Within public land,
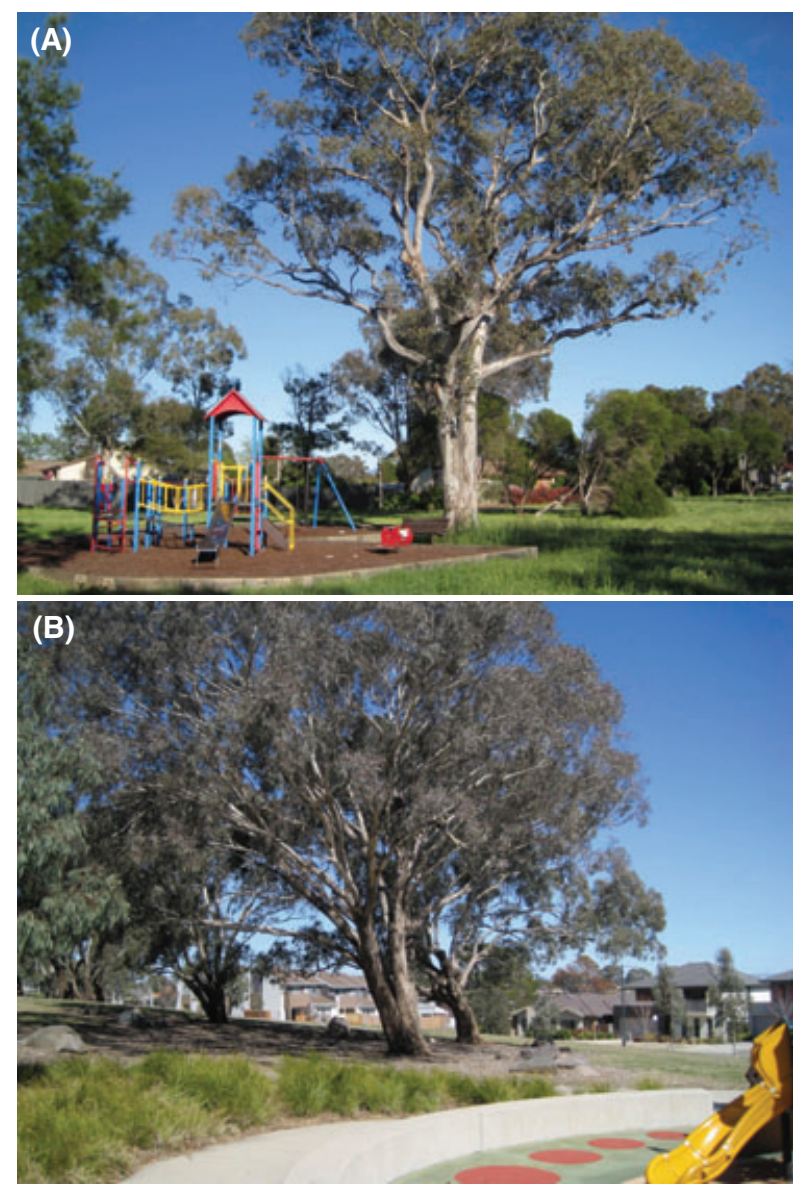

Figure 1 (A) Example of a typical urban park with a large tree (Burrinjuck Crescent Neighborhood Park, Duffy, Canberra, Australia). (B) Example of planned landscaping separating children's play area (foreground) and large trees (Heritage Park, Forde, Canberra, Australia).

there are several categories of urban parkland, ranging from large formally managed town parks to informal district parks, small neighborhood parks, pedestrian parkland and laneways, and informal-use sporting fields (ACT Government 2006). We chose to focus on neighborhood parks, which are typically used for recreation and often include playground facilities (Figure 1A). Neighborhood parks are located in residential areas, are usually 0.25-2 ha in area, and are spaced so that every dwelling is generally within $400 \mathrm{~m}$ of a park (ACT Government 2006). As such, these parks may provide a continuum of wildlife habitat throughout urban areas, and their appropriate management is important for urban conservation. We identified neighborhood parks that were between 0.5 ha and 2 ha, contained native trees of the genus Eucalyptus, were $>500 \mathrm{~m}$ from other parks, $>250 \mathrm{~m}$ from nature reserves, and in suburbs where the median residential block size was between $200 \mathrm{~m}^{2}$ and $1,100 \mathrm{~m}^{2}$. We placed a 50-m radius (0.8 ha) site at the geographic centroid of 
each park. We then excluded parks that had $<60 \%$ of total site area (i.e., $<0.5$ ha) within the park boundaries. This selection process gave us sites in 109 neighborhood parks, from an original total pool of 337 parks.

\section{Park trees and vegetation}

We measured the trunk diameter at breast height (DBH; $1.3 \mathrm{~m}$ above ground level) of all live eucalypt trees within the site. For trees with multiple stems at breast height, we measured the diameter of each stem, and used the summed basal area to calculate the equivalent diameter for a single-stemmed tree with the same basal area at breast height (following Fischer et al. 2009). We then aggregated this data to the site scale by calculating the number of "large" eucalypt trees per hectare. There are several ways to define large trees in the academic literature and management policies, ranging from greater size and age compared to neighboring trees (e.g., Mazurek $\delta$ Zielinski 2004; Loyn \& Kennedy 2009) to specified minimum trunk diameters (e.g., Harper et al. 2005; deMars et al. 2010). Because of these differing definitions, we chose not to explicitly define large trees but instead to investigate a range of minimum trunk diameters. We therefore calculated the number of eucalypt trees per hectare in each site with a DBH $>0 \mathrm{~cm}$ (all trees) and the number of trees per hectare in 10 other minimum diameter size classes, ranging from $\mathrm{DBH}>10 \mathrm{~cm}$ to $\mathrm{DBH}>100 \mathrm{~cm}$. These measures corresponded to a conservative estimate of tree age, as the age of eucalypts is positively associated with tree diameter (Koch et al. 2008).

We also recorded within each site: (1) the total number of trees per hectare (of all species), (2) the proportion that were eucalypts, (3) the presence of shrubs, (4) the percentage cover of leaf litter, and (5) the percentage cover of grass. We ran a principal components analysis on these five variables to characterize the vegetation of each park, log-transforming percent shrub and leaf litter cover before analysis because these variables were highly skewed (Table S1). We used this principal component (vegetation index) to adjust for differences in park vegetation cover between sites in later analyses.

\section{Birds}

We surveyed each site for birds using 10-minute 50-m radius point counts. We conducted two separate morning surveys in spring 2010, and avoided rainy or windy days. We recorded the presence and abundance of all species seen or heard, as well as the incidence of breeding by any species (see Table S2 for breeding definitions). All of the parks had open vegetation and clear lines of sight; we were therefore confident that we detected all birds present during our surveys. We used a list developed by Birds Australia to identify bird species associated with woodland habitats (Silcocks et al. 2005) to determine woodland species richness. Finally, we performed a correspondence analysis (CA) of species presence/absence data to summarize the community structure of birds at each site. This ordination technique scores species on the basis of the sites were they occur (CA species scores) and scores sites on the basis of the species they contain (CA site scores), and maximizes the correlation between the two scores. This gradient of CA species scores was positively correlated with CA site scores $(R=0.49)$, and so we used the CA site scores as a proxy for community composition.

\section{Data analysis}

To assess whether large trees were having an effect on bird diversity, we fitted generalized linear models for five bird responses: species richness, average abundance, probability of breeding, woodland species richness, and community composition. For each of these responses, we fitted 11 separate models, with a different value of "trees per hectare" for each DBH size class, ranging from DBH $>0 \mathrm{~cm}$ (all trees) to $\mathrm{DBH}>100 \mathrm{~cm}(55$ models in total), to investigate whether the strength of the effect of large trees increased with increasing trunk diameter. To account for differences in vegetation between sites, we fitted the vegetation index first in the models (i.e., response $=$ vegetation index + trees per hectare). We fitted models with a Poisson error distribution and log link function, except for the models for probability of breeding (binomial distribution and logit link function) and the community composition models (normal distribution and identity link function). Before fitting the models, we used spline correlograms to confirm that there was no spatial autocorrelation between sites. For each of the bird responses, we examined and compared the estimated effect sizes (regression coefficients) and fitted models. We considered the effect sizes to be strong when the 95\% confidence interval did not include 0.0. To aid our model comparisons, we ranked the models using the Akaike Information Criterion (AIC; Burnham \& Anderson 2002).

\section{Results}

We recorded 44 bird species (Table S2), with an average of 7.8 ( \pm 2.6 standard deviation) species, 11.5 ( \pm 6.2$)$ individual birds and $3.5( \pm 1.5)$ woodland species per site. We recorded the incidence of breeding at $49 \%$ of sites. The gradient in community composition ranged from species that were smaller-bodied and shrub-dependent 
to species that were larger-bodied and tree-dependent (Figure S1). We measured 3,300 eucalypt trees, with an average of 49.1 trees per ha $( \pm 39.6)$.

The number of eucalypt trees per hectare had a positive effect on bird richness (Figure 2A), average abundance (Figure 2B), probability of breeding (Figure 2C), woodland species richness (Figure 2D), and community composition scores (Figure 2E) in 52 of the 55 models we constructed (Table S3). In contrast, we did not find a strong or consistent effect of the site vegetation index on any of the bird responses (Figure S2).

The effect size of trees per hectare was weak (i.e., the confidence interval included 0.0) until trees reached a minimum threshold diameter (Figure 2, Table S3). We found that the effect size was weak until trees were $>50$ $\mathrm{cm}$ for species richness, $>50 \mathrm{~cm}$ for average abundance, $>40 \mathrm{~cm}$ for probability of breeding, $>40 \mathrm{~cm}$ for woodland species richness, and $>50 \mathrm{~cm}$ for community composition. For all bird responses, the best-ranked models (lowest AIC) were those where tree diameters were large (DBH at least $80 \mathrm{~cm}$; Table S3).

As the diameter of the trees increased, the magnitude of the effect size also increased (Figure 2, Table S3). When compared to increases after the addition of five random trees to a park, the addition of five trees $>100 \mathrm{~cm}$ increased species richness by 157\%, average abundance by $91 \%$, probability of breeding by $158 \%$, and woodland species richness by $301 \%$.

\section{Discussion}

Large trees are considered keystone structures in agricultural and forestry production landscapes because they are crucial for ecosystem function and provision of habitat resources (Tews et al. 2004). Our study is the first to explicitly demonstrate that large trees are also keystone structures in urban parks. This is because they have a consistent, positive, and strong relationship with bird richness, average abundance, presence of breeding, woodland species richness, and community composition. Furthermore, we confirmed that as trees became larger in size, their positive effect on bird diversity also increased. To our knowledge, this finding has not been previously demonstrated directly for bird fauna, although several studies have identified a similar pattern between large trees and structural characteristics (e.g., hollows: Lindenmayer et al. 1993; Harper et al. 2005; coarse woody debris: Killey et al. 2010).

Large trees provide structural complexity not offered by smaller trees. For example, Mazurek $\&$ Zielinksi's (2004) study of Californian commercial forest found that young redwood (Sequoia sempervirens) trees lacked large horizontal limbs, basal hollows, and cavities, which probably lowered their attractiveness to wildlife compared with older and larger trees. In Australia, 15\% of terrestrial vertebrates use eucalypt hollows (Gibbons $\delta$ Lindenmayer 2002), and Harper et al. (2005) found that the probability of live eucalypt trees having at least one hollow increased as trunk diameter increased. Similarly, in France, Sirami et al. (2008) found that the availability of large pieces of dead wood, critical habitat for saproxylic beetles, was positively correlated with tree size. Large trees also provide disproportionate quantities of flowers, pollen, nectar, seed set, mistletoe, and hanging bark, which are important food and microhabitat resources for a range of invertebrate and vertebrate species (Lindenmayer \& Franklin 1997, and references therein). Furthermore, within the urban context in particular, large trees may provide places of concealment and act as essential refuges from human disturbances, such as recreation and traffic noise (Fernandez-Juricic et al. $2001)$.

More specific research quantifying the importance of large trees in urban areas for wildlife would be valuable for urban management, particularly if focused on a range of vertebrate and invertebrate taxa. Further research on how the role of large urban trees changes with different urban settings and/or urban densities is also needed, especially for mobile taxa such as birds that are affected by local landscape context (Lim \& Sodhi 2004; Sattler et al. 2010).

Because large urban trees provide important habitat resources for wildlife, it is vital that they are managed appropriately. The loss of large trees from urban settings may have far-reaching ecological consequences that may undermine other biodiversity conservation measures. Harper et al. (2005, p. 187) for example, concluded that a lack of large hollow-bearing trees was "possibly the greatest threat to the short-term $(<20$ years) ecological sustainability" of urban remnants within their study region in southeastern Australia. This is particularly pertinent in urban areas where management policies often cause trees to be felled or extensively pruned before they reach their full biological potential (Jim 2004, 2005; Carpaneto et al. 2010), thereby limiting their value to wildlife. For example, we found that species richness increased by approximately $10 \%$ with the addition of five $>50 \mathrm{~cm}$ trees but by over $150 \%$ with the addition of five $>100 \mathrm{~cm}$ trees. For richness of woodland dependent species, the increase was over $300 \%$. On the basis of these results, we argue for the preservation of very large trees $(>100 \mathrm{~cm})$ in urban areas, and their prioritization over other management considerations when policies conflict. Risk posed by large, old trees should be managed by strategies other than tree removal, for example fencing or landscaping (Figure 1B). 


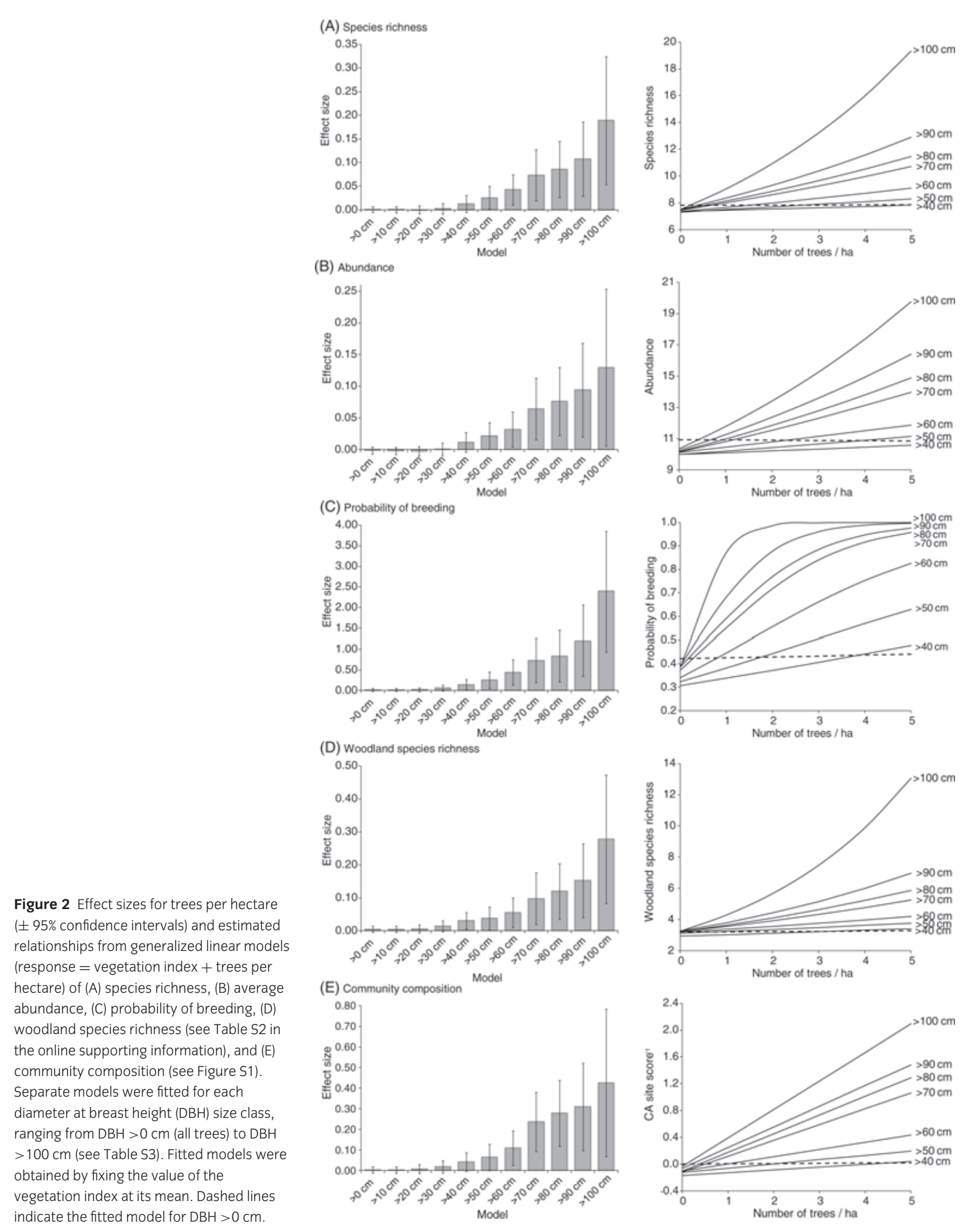

Figure 2 Effect sizes for trees per hectare ( \pm 95\% confidence intervals) and estimated relationships from generalized linear models response $=$ vegetation index + trees per vegetation index at its mean. Dashed lines indicate the fitted model for $\mathrm{DBH}>0 \mathrm{~cm}$.
(B) Abundance

(C) Probability of breeding

(E) Community composition 
Table 1 Selected examples of urban tree protection policies worldwide that are based on physical criteria

\begin{tabular}{|c|c|c|c|}
\hline Region & Managing authority & Policy & Physical criteria for protection \\
\hline \multirow[t]{4}{*}{ North America } & Redwood City, California, USA & Tree Preservation Ordinance & Any private property tree $>30-\mathrm{cm}$ trunk diameter \\
\hline & City of Austin, Texas, USA & $\begin{array}{l}\text { Tree and Natural Area Preservation } \\
\text { Ordinance }\end{array}$ & Any tree $>50-\mathrm{cm}$ trunk diameter \\
\hline & $\begin{array}{l}\text { City of Victoria, British } \\
\text { Columbia, Canada }\end{array}$ & Tree Preservation Bylaw (No. 05-106) & $\begin{array}{l}\text { Listed native species }>50-\mathrm{cm} \text { height, listed native species } \\
>60-\mathrm{cm} \text { trunk diameter, and any private property tree } \\
>80-\mathrm{cm} \text { trunk diameter }\end{array}$ \\
\hline & $\begin{array}{l}\text { City of Kingston, Ontario, } \\
\text { Canada }\end{array}$ & Tree Bylaw (No. 2007-170) & Any tree $>15-\mathrm{cm}$ trunk diameter \\
\hline \multirow[t]{2}{*}{ Europe } & Bratislava, Slovakia & $\begin{array}{l}\text { Act of the National Council of the } \\
\text { Slovak Republic No. } 287 / 1994 \text { : On } \\
\text { the Preservation of Nature And } \\
\text { Landscape }\end{array}$ & Any tree $>50-\mathrm{cm}$ trunk diameter \\
\hline & City of Dublin, Ireland & Zoning Code (§153.141) & Any tree $>15-\mathrm{cm}$ trunk diameter \\
\hline Asia & Singapore & Parks and Trees Act 1996 & Any tree > 30-cm trunk diameter \\
\hline \multirow[t]{2}{*}{ Australia } & City of Sydney & Tree Preservation Order 2004 & $\begin{array}{l}\text { Any tree }>5-\mathrm{m} \text { height or }>10-\mathrm{cm} \text { trunk diameter or }>30-\mathrm{cm} \\
\text { aggregated diameter (multiple trunks) }\end{array}$ \\
\hline & $\begin{array}{l}\text { Canberra, Australian Capital } \\
\text { Territory }\end{array}$ & Tree Protection Act 2005 & $\begin{array}{l}\text { Any tree }>12-\mathrm{m} \text { height, }>12-\mathrm{m} \text { crown width, or }>50-\mathrm{cm} \\
\text { trunk diameter (this can be split between multiple trunks) }\end{array}$ \\
\hline
\end{tabular}

Our results conflict with existing tree protection policy in urban open space in many jurisdictions. We found that trees as small as $40 \mathrm{~cm}$ in diameter can have a strong positive effect on bird diversity, which is smaller than minimum sizes prescribed by many managing authorities, including in North America, Europe, Asia, and Australia (Table 1). In our study area, government law regulates only the removal of trees $>50 \mathrm{~cm}$ in diameter, so that 457 park trees $40-49 \mathrm{~cm}$ in diameter (14\% of all trees that we measured) do not receive formal protection. Similar numbers of trees may be at risk in other cities worldwide where the physical criteria for tree regulation focus on larger trunks (Table 1). Tree preservation laws, therefore, may not be providing adequate protection for a large number of important trees. We suggest that physical criteria for protection as part of tree preservation policies should be evidence-based and regularly reviewed and that the value of large trees for biodiversity be explicitly acknowledged.

Finally, our findings reiterate the importance of proactively planning for future large trees (Jim 2004). It takes many decades for a newly planted sapling to become a large tree (Koch et al. 2008). Within urban areas, it is thus critical for long-term sustainability to actively manage for a diversity of tree ages, so that younger trees may eventually replace mature and over-mature trees (Harper et al. 2005; Millward \& Sabir 2011). These younger trees may also provide important structural habitat for wildlife complementing that provided by large trees (Munro et al. $2011)$.
In conclusion, we have unequivocally demonstrated that large trees are of critical value in urban areas as keystone structures. Worldwide, large trees are declining in a range of human-managed ecosystems, including agricultural areas (Gibbons et al. 2008), forestry production regions (Gibbons et al. 2010), and urban landscapes (Jim 2005; Grigg et al. 2009). Negative consequences for biodiversity have been predicted as a result of this decline (Fischer et al. 2009; Fischer et al. 2010a, and references therein). This threat is exacerbated by the substantial amount of time needed before younger trees are capable of providing the same level of habitat resources as large trees (Lindenmayer et al. 1993; Harper et al. 2005). For the best possible conservation of large trees and their ongoing existence into the future, it is urgent that the value of large trees for biodiversity is recognized in urban management and planning policies. With evidencebased tree preservation policies and the specific recognition that large trees are critical for biodiversity, the protection and perpetuation of these important keystone structures could be achieved.

\section{Acknowledgments}

Thanks to staff from ACT Conservation, Planning and Research, Territory and Municipal Services; Land Development Agency, ACT Planning and Land Authority; Jeff Wood for help with statistical analysis; and Phil Gibbons, Philip Barton, Pia Lentini, and Ben Scheele for providing helpful comments on an earlier version of this 
article. K.S. was the recipient of a postgraduate independent research scholarship, jointly funded by the Fenner School of Environment and Society (The Australian National University) and Conservation, Planning and Research (ACT Government). Ethics approval was obtained before conducting this work (F.ES.08.10).

\section{Supporting Information}

Additional Supporting Information may be found in the online version of this article:

Figure S1: Summary of correspondence analysis (CA) scores for species.

Figure S2: Effect sizes for vegetation index $( \pm 95 \%$ confidence intervals) from generalized linear models (response $=$ vegetation index + trees per hectare) of (A) species richness, (B) average abundance, (C) probability of breeding, (D) woodland species richness (see Table S2), and (E) community composition (see Figure S1).

Table S1: Summary of principal components analysis (vegetation index).

Table S2: Complete list of observed bird species. Nomenclature is taken from Christidis \& Boles (2008) and woodland species classification follows Silcocks et al. (2005).

Table S3: Generalized linear models (response = vegetation index + trees per hectare) for (A) species richness, (B) average abundance, (C) probability of breeding, (D) woodland species richness, and (E) community composition.

Please note: Wiley-Blackwell is not responsible for the content or functionality of any supporting materials supplied by the authors. Any queries (other than missing material) should be directed to the corresponding author for the article.

\section{References}

ABS (2010) Australian Demographic Statistics, 3101.0, Dec 2010. Australian Bureau of Statistics.

ACT Government (2006) Design standards for urban infrastructure. 14. Urban Open Space. Territory and Municipal Services, ACT.

Burnham, K.P., Anderson, D.R. (2002) Model selection and multimodel inference. Springer, New York.

Carpaneto, G.M., Mazziotta, A., Coletti, G., Luiselli, L., Audisio, P. (2010) Conflict between insect conservation and public safety: the case study of a saproxylic beetle (Osmoderma eremita) in urban parks. J Insect Conserv 14, 555-565.

Christidis, L., Boles, W. (2008) Systematics and taxonomy of Australian birds. CSIRO Publishing, Collingwood.
deMars, C.A., Rosenberg, D.K., Fontaine, J.B. (2010) Multi-scale factors affecting bird use of isolated remnant trees in agro-ecosystems. Biol Conserv 143, 1485-1492.

Fernandez-Juricic, E., Jimenez, M.D., Lucas, E. (2001) Bird tolerance to human disturbance in urban parks of Madrid (Spain): Management implications Pages 259-273 in J.M. Marzluff, R. Bowman, and C. Donnelly, editors. Avian ecology and conservation in an urbanizing world. Kluwer Academic Publishers, Boston, MA.

Fischer, J., Stott, J., Zerger, A., Warren, G., Sherren, K., Forrester, R.I. (2009) Reversing a tree regeneration crisis in an endangered ecoregion. Proc Natl Acad Sci U S A Biol Sci 106, 10386-10391.

Fischer, J., Stott, J., Law, B. (2010a) The disproportionate value of scattered trees. Biol Conserv 143, 1564-1567.

Fischer, J., Zerger, A., Gibbons, P., Stott, J., Law, B. (2010b) Tree decline and the future of Australian farmland biodiversity. Proc Natl Acad Sci U S A Biol Sci 107, 19597-19602.

Gibbons, P., Boak, M. (2002) The value of paddock trees for regional conservation in an agricultural landscape. Ecol Manage Restor 3, 205-210.

Gibbons, P., Lindenmayer, D.B. (2002) Tree hollows and wildlife conservation in Australia. CSIRO Publishing, Collingwood.

Gibbons, P., Lindenmayer, D.B., Fischer, J. et al. (2008) The future of scattered trees in agricultural landscapes. Conserv Biol 22:1309-1319.

Gibbons, P., McElhinny, C. ,Lindenmayer, D.B. (2010) What strategies are effective for perpetuating structures provided by old trees in harvested forests? a case study on trees with hollows in south-eastern Australia. For Ecol Manage 260, 975-982.

Grigg, A., Close, D.C., Lambers, H., Ruthrof, K.X., Dixon, K.W. (2009) Ecophysiology of Eucalyptus marginata and Corymbia calophylla in decline in an urban parkland. Austral Ecol 34, 499-507.

Harper, M.J., McCarthy, M.A., van der Ree, R. (2005) The abundance of hollow-bearing trees in urban dry sclerophyll forest and the effect of wind on hollow development. Biol Conserv 122, 181-192.

Jim, C. (2004) Evaluation of heritage trees for conservation and management in Guangzhou city (China). Environ Manage 33, 74-86.

Jim, C. (2005) Monitoring the performance and decline of heritage trees in urban Hong Kong. J Environ Manage 74, 161-172.

Killey, P., McElhinny, C., Rayner, I., Wood, J. (2010) Modelling fallen branch volumes in a temperate eucalypt woodland: implications for large senescent trees and benchmark loads of coarse woody debris. Austral Ecol 35, 956-968.

Koch, A.J., Driscoll, D., Kirkpatrick, J. (2008) Estimating the accuracy of tree ageing methods in mature Eucalyptus obliqua forest, Tasmania. Aust For 71, 147-159. 
Lim, H.C., Sodhi, N.S. (2004) Responses of avian guilds to urbanisation in a tropical city. Landsc Urban Plan 66, 199-215.

Lindenmayer, D., Wood, J., McBurney, L. et al. (2011) Cross-sectional versus longitudinal research: a case study of trees with hollows and marsupials in Australian forests. Ecol Monogr 81, 557-580.

Lindenmayer, D.B., Cunningham, R.B., Donnelly, C.F., Tanton, M.T., Nix, H.A. (1993) The abundance and development of cavities in Eucalyptus trees: a case study in the montane forests of Victoria, southeastern Australia. For Ecol Manage 60, 77-104.

Lindenmayer, D.B., Franklin, J. (1997) Managing stand structure as part of ecologically sustainable forest mangament of mountain ash forests. Conserv Biol 11, 1053-1068.

Loyn, R., and Kennedy, S. (2009) Designing old forest for the future: old trees as habitat for birds in forests of Mountain Ash Eucalyptus regnans. For Ecol Manage 258, 504-515.

Lumsden, L.F., and Bennett, A.F. (2005) Scattered trees in rural landscapes: foraging habitat for insectivorous bats in south-eastern Australia. Biol Conserv 122, 205-222.

Manning, A.D., Fischer, J., Lindenmayer, D.B. (2006) Scattered trees are keystone structures-implications for conservation. Biol Conserv 132, 311-321.

Manning, A.D., Gibbons, P., Lindenmayer, D.B. (2009) Scattered trees: a complementary strategy for facilitating adaptive responses to climate change in modified landscapes? J Appl Ecol 46, 915-919.

Mazurek, M., Zielinski, W.J.. (2004) Individual legacy trees influence vertebrate wildlife diversity in commercial forests. For Ecol Manage 193, 321-334.

Millward, A.A., Sabir, S. (2011) Benefits of a forested urban park: what is the value of Allan Gardens to the city of Toronto, Canada? Landsc Urban Plan 100, 177-188.

Munro, N., Fischer, J., Barrett, G. et al. (2011) Bird's response to revegetation of different structure and floristics-are "restoration plantings" restoring bird communities. Restor Ecol 19, 223-235.

Ortega-Alvarez, R., MacGregor-Fors, I. (2010) What matters most? Relative effect of urban habitat traits and hazards on urban park birds. Ornitol Neotrop 21, 519-533.
Pauleit, S., Ennos, R., Golding, Y. (2005) Modeling the environmental impacts of urban land use and land cover change-a study in Merseyside, UK. Landsc Urban Plan 71, 295-310.

Poulson, B.O. (2002) Avian richness and abundance in temperate Danish forests: tree variables important to birds and their conservation. Biodivers Conserv 11, 15511566.

Rolo, V., Moreno, G. (2011) Shrub species affect distinctively the functioning of scattered Quercus ilex trees in Mediterranean open woodlands. For Ecol Manage 261, 1750-1759.

Sattler, T., Borcard, D., Arlettaz, R. et al. (2010) Spider, bee, and bird communities in cities are shaped by environmental control and high stochasticity. Ecology 91, 3343-3353.

Seymour, C.L., Dean, W.R.J. (2010) The influence of changes in habitat structure on the species composition of bird assemblages in the southern Kalahari. Austral Ecol 35, 581-592.

Silcocks, A., Tzaros, C., Weston, M., Olsen, P. (2005) An interim guild classification for woodland and grassland birds in Australia. Birds Australia Supplementary Report. Birds Australia, Carlton.

Sirami, C., Jay-Robert, P., Brustel, H., Valladares, L., Le Guilloux, S., Martin, J.-L. (2008) Saproxylic beetle assemblages of old holm-oak trees in the Mediterranean region: role of a keystone structure in a changing heterogeneous landscape. Revue d'Ecologie (la Terre et la Vie) 63, 93-106.

Stagoll, K., Manning, A.D., Knight, E., Fischer, J., Lindenmayer, D.B. (2010) Using bird-habitat relationships to inform urban planning. Landsc Urban Plan $\mathbf{9 8 ,}$ 13-25.

Tews, J., Brose, U., Grimm, V. et al. (2004) Animal species diversity driven by habitat heterogeneity/diversity: the importance of keystone structures. J Biogeogr 31, 79-92.

Vesk, P.A., Mac Nally, R. (2006) The clock is ticking revegetation and habitat for birds and aboreal mammals in rural landscapes of southern Australia. Agricult Ecosys Environ 112, 356-366. 